\title{
RESENHA
}

\section{MARIA COM MARCEL, OU: RELEITURAS DA MODERNIDADE PERIFÉRICA}

ANTELO, Raúl. Maria com Marcel: Duchamp nos trópicos. Belo Horizonte: UFMG, 2010 .

\author{
Maria Salete Borba*
}

Em Maria com Marcel: Duchamp nos trópicos, de Raúl Antelo, encontramos uma leitura da história da América Latina pelo viés da arte, dos agenciamentos entre literatura e outras formas artísticas como, por exemplo, a escultura barroco/surrealista de Maria Martins. Ou podemos dizer, também, que Antelo apresenta uma relação entre "corpos" atravessada pela filosofia, psicanálise e pela história cultural, como afirma ao comentar que seu livro "é uma leitura do corpo e do mundo" (p. 10). Em Maria com Marcel encontramos, além da reconstituição da estada de Marcel Duchamp em Buenos Aires, na primeira metade do século XX, mais especificamente de setembro de 1918 a junho de 1919, a consolidação das investigações de Antelo em torno da teoria da modernidade. Assim, vislumbramos ora o labirinto constituído pela pesquisa, pela exposição do arquivo realizada pelo professor/arqueólogo/curador, ora aquele labirinto lido a partir dos contatos com os escritos de Georges Bataille, especialmente os textos publicados na revista Documents.

Muito já se falou de Maria com Marcel desde seu lançamento em língua espanhola pela Siglo Veintiuno em 2006. Porém, poucos sabem que Maria com Marcel foi escrito em português, e que a versão em espanhol é uma tradução do professor argentino Mário Câmara, como revela, em conversa, Raúl Antelo. Alguns críticos, além de apresentarem os méritos da obra, dialogam reafirmando o respeito e o reconhecimento pelo trabalho do autor. $\mathrm{O}$ catedrático de História da Arte na Universidade de Buenos Aires, José E. Burucua, registrou seu reconhecimento em reportagem para o website oficial da Universidade Federal de Santa Catarina, onde declara que "se trata de un texto de tal riqueza de inventiva, de tal capacidad de demostración de las conexiones históricas entre los diversos campos de la cultura, que podría considerárselo uno de los mayores ejemplos mundiales de la historiografía cultural"".

Eliane Robert Morais, na resenha "Sulrealismo à vista", , sublinha alguns pontos relevantes de Maria com Marcel. Por exemplo, o fato de Duchamp ter qualificado a sua passagem por Buenos Aires de "aborrecida, mas produtiva", e que a maioria dos críticos

\footnotetext{
* Pós-doutoranda na Universidade Federal de Santa Catarina (UFSC).

${ }^{1} \mathrm{http}: / /$ www.onetti.cce.ufsc.br/simposio/textosinvitados/textosdiv/criticasantelo.pdf

2 http://sergyovitro.blogspot.com/2011/02/sulrealismo-vista-eliane-robert-moraes.html
} 
detiveram-se somente no primeiro termo, enquanto que Raúl Antelo debruça-se, justamente, sobre o segundo, reivindicando a atenção para a produtividade. Conforme explica a autora, "[u]m bom exemplo está na conhecida Mona Lisa de bigodinhos e cavanhaque, à qual Duchamp acrescentou as iniciais $L . H$. O.O.Q. que, pronunciadas em francês, produzem um som semelhante ao da expressão brasileira "ela tem fogo no rabo". Moraes continua sua leitura, enfatizando que "[d]atado de 1919, logo após o retorno de seu criador à França, esse ready-made [L. H. O. O. Q.] pode ter se alimentado dos novos meios culturais de massa que aportavam na Buenos Aires daqueles anos. Entre as novidades que anunciavam a modernização da cidade, com forte impacto sobre o gosto médio urbano, estava a marmelada La Gioconda, doce comercializado em lata redonda, com o ícone de Leonardo estampado em série, que pode ter sido para Duchamp o mesmo que viria a ser a Campbell's Soup para Andy Warhol".

Já Analía Gerbaudo, da Universidad Nacional del Litoral - CONICET, no texto "Poscrítica y teoría literaria en América del Sur: apuntes a propósito de una obra", detém-se na leitura do procedimento de Raúl Antelo, o qual é incluído no termo póscrítica: "Antelo desmantela el binomio centro/periferia a partir de la lectura de los procesos que generaron las modernidades y de la reconstrucción de las operaciones de la teoría y de la crítica latinoamericanas". Afirma ainda que "a partir de otros datos, esta posición de Antelo se dejaba entrever en Tempos de Babel: anacronismo e destruição y también en María con Marcel: Duchamp en los trópicos: hay en la sólo aparente periferia la emergencia de acontecimientos o fenómenos que, desatendidos hasta cierto momento de la historia, revelan [...] la necesidad de volver a cartografiar la zona". Tal cartografia, assinala Gerbaudo, é "tarea que sólo una 'insuperable desconfianza' y una 'disponibilidad permanente para reconocer que todo en ella puede estar equivocado, 3 permiten realizar". Ainda em seu texto Analía Gerbaudo lembra e cita outro crítico argentino, Daniel Link: “en María con Marcel se dejaba leer la hipótesis, extravagante y por eso mismo, encantatoria, de que Duchamp no habría llegado a nada sin la experiencia de lo americano (una categoría que incluye, o debería incluir, por supuesto, a los Estados Unidos)".

Eduardo Sterzi, poeta, jornalista e professor, também escreve, em 2006, por ocasião da primeira publicação de Maria com Marcel, a resenha "Com Maria e Marcel, à margem" . Em sua resenha, ele destaca como Raúl Antelo, desde Na ilha de Marapatá (1984), até Maria com Marcel, vem lendo os possíveis laços entre política e cultura. Para tanto, Sterzi lê nesta suposta continuidade da narrativa a certeza de que Antelo, em Maria com Marcel, vem "escrever a história daquilo que, em outro ensaio, designou "contra-modernidade pós-nacional das margens" (p. 5) Para tanto, justifica Sterzi a convocação que Antelo faz de uma infinidade de artistas e filósofos, entre outros esquecidos pela história: "entre os brasileiros, não só Maria Martins, conduzida finalmente à posição destacada que sempre lhe coube na cultura do século XX (e isto em dimensão planetária, não só nacional), mas também Flávio de Carvalho e Raul Bopp" (p. 5). Sterzi lembra, também, o repertório de artistas estrangeiros que habitam o

\footnotetext{
${ }^{3}$ Tempos de Babel: anacronismo e destruição. São Paulo: Lumme, 2000. p. 9.

4 "Com Maria e Marcel, à margem" foi escrito em setembro de 2006 - por ocasião do lançamento da edição argentina de Maria con Marcel: Duchamp en los trópicos - e publicado no quinto número do $K-$ Jornal de Crítica. A tradução da resenha foi publicada no Sopro, n. 36 (http://culturaebarbarie.org/sopro/n36.pdf) por ocasião da tradução brasileira ampliada de Maria com Marcel: Duchamp nos trópicos, pela UFMG.
} 
livro dedicado a Duchamp: "entre os de fora, o catálogo de nomes é proliferante, indo do antropólogo alemão Robert Lehmann-Nitsche [...] ao poeta e artista caboverdiano Antonio Pedro (introdutor do surrealismo em Portugal, amigo de Duchamp), passando, no caminho, por inúmeras iscas - nomes de autores, títulos de obras - para futuras leituras e releituras" (p. 5).

Ainda sobre a edição em língua espanhola, lemos a resenha ${ }^{5}$ de Luis Othoniel Rosa, professor na Duke University, onde é trazido à tona Raúl Antelo como curador de momentos históricos. Em sua resenha, Rosa aproxima Antelo de Borges fazendo referência ao colecionador enciclopédico que se transforma em um "curador de un archivo paranoico, y, como Borges, su escritura se sostiene en su comentario a lo labor del otro, aunque ese otro sea un Pierre Menard, efectivamente convirtiendo al curador en artista”. Nesta galeria, Othoniel Rosa lê três momentos ou motivos argumentativos: "[e]l primer motivo yace en una suerte de teoría de la imagen en las vanguardias frente a la modernidad. [...] El segundo motivo es la mirada sobre el primitivismo, y sobre el mundo no occidental, sobre una búsqueda de mundos que no se rigen por los principios del individuo liberal de la modernidad occidental. [...] El tercer motivo, muy ligado al segundo, es entonces el aspecto periférico de las vanguardias".

Dando continuidade a essas múltiplas leituras que enfatizam ora detalhes da obra, ora a importância do método do crítico, podemos sublinhar que além do que já foi escrito há vários outros aspectos que podem ser comentados em Maria com Marcel: Duchamp nos trópicos. Logo na introdução, "O vidro e os insetos", somos colocados em contato tanto com os objetivos quanto com as questões teóricas que vão atravessar o livro. Nas primeiras linhas, Raúl Antelo esclarece que o propósito do livro "é reconstruir o sistema de saber de um conjunto heterogêneo, quando não abertamente miscelâneo, de objetos culturais que guarda estreita relação com a cultura latinoamericana" (p. 9). Além de deixar claro que se trata de material heterogêneo e da América Latina, Antelo acrescenta que "[o] eixo ao redor do qual gira toda a construção é a figura de Marcel Duchamp (1887-1968) (p. 9)". No entanto, é importante frisar, o destaque dado à escultora Maria Martins, que nos é apresentada não somente como musa inspiradora de Duchamp mas, principalmente, como uma artista multifacetária, como lemos nas palavras de sua filha Nora Martins, que servem de epígrafe para o terceiro capítulo de Maria com Marcel, intitulado "O impossível”:

Minha mãe, Maria, foi muitas pessoas na verdade. Para começar, ela era muito bonita, o que ajuda, e era uma escultora, uma artista, uma excelente embaixatriz, uma poeta, uma escritora e foi extremamente interessada em tudo. Era curiosa. Queria aprender. Costumava dizer que o dia em que você para de aprender, você morre. Foi uma pessoa complexa e cheia de charme [...] (p. 117).

Antelo, por sua vez, nos apresenta uma Maria batailleana, que além de "aplicar os preceitos de forma cunhados por Apollinaire" (p. 138), lê o nascimento da arte como Bataille, nas grutas:

As mais remotas épocas nos legaram pintadas, esculpidas ou gravadas, imagens que nos transmitem, até hoje, a magia de suas religiões, de seus mitos, de suas lendas, de seus ódios e de seus amores. Aqueles homens incipientes, em contínua e acerba luta com a natureza, cercados de perigos sempre novos, sedentos de beleza, semearam nas cavernas escuras, onde

\footnotetext{
${ }^{5}$ http://elroommate.com/2011/09/23/luis-othoniel-resena-a-raul-antelo-argentina/
} 
viviam, as primeiras obras de arte (p.138).

Assim, outra face de Maria Martins nos é revelada, tal como Raúl Antelo sublinha quando comenta os parâmetros da crítica brasileira representada por Mário Pedrosa, seguidor de Greenberg, que lê na escultura de Martins uma falta de monumentalidade. Além disso, afirma Pedrosa que "[e]la [Maria Martins] tem da escultura uma concepção literária e, por isso mesmo, romântica" (p. 137). Ou seja, ao contrário de Mário Pedrosa, Antelo rearma a leitura e lê Maria Martins apontando justamente o que é ignorado por Pedrosa, ou seja, a erudição, os contatos que além de brilho e grandiosidade dão consistência ao trabalho da escultora.

Por essas leituras instigantes é que Maria com Marcel aguça a curiosidade do leitor a cada página. Antelo continua neste ritmo capítulos afora e presenteia o leitor com uma Maria muito mais exuberante, ultrapassando tanto a alcunha da embaixatriz, quanto a da amante de Duchamp. Neste livro, Maria Martins é amante das artes e do orientalismo, ao mesmo tempo em que se aproxima da filosofia, do hiper-historicismo nietzschiano. A Maria Martins que fica depois da leitura de Maria com Marcel é aquela que ultrapassa todas as classificações, que está além do romance, que se despe nas trocas intelectuais com Marcel Duchamp, conforme lembra Antelo:

\begin{abstract}
Não nos esqueçamos das linhas em que Marcel Duchamp descreve o ato de criação como uma sorte de fusão nietzschiano-heideggeriana. Por isso, não surpreende que, ao ser interrogada sobre a questão da duração e da eternidade, Maria Martins fale pela boca de Duchamp ou que, ao contrário, quando Duchamp queira pensar o para além da matéria, lembre do conselho de Maria.

Com efeito, em uma entrevista concedida a $O$ jornal (Rio de Janeiro, 9 de novembro de 1956), a escultora diz: "tenho alma de cigana e ser-me-ia profundamente ingrato ter que firmar pés na terra, em determinado lugar, até a visita da morte (aliás, não morremos, são os outros que morrem)". A frase, como sabemos, será copiada por Duchamp como seu epitáfio, “...et d'ailleurs/ c'est toujours les autres qui meurent" (p. 141).
\end{abstract}

Nesse ínterim, vale lembrar também de alguns pontos estruturais deste livro, que, ainda na introdução, traz à baila a Buenos Aires marcada pela Greve Geral, período que ficou conhecido como a Semana Trágica e aproxima, assim, Pinnie Wald, o presidente da Rebelião Maximalista argentina de janeiro de 1919, de Marcel Duchamp. Na edição brasileira, esta seção nos é apresentada escandida em cinco partes: "Pesadelo e retorno", "Movimento e comunidade negativa", "Dados", "O encontro do objet-d'art" e "Mise à nu ou desnudamento".

O livro dedicado a Marcel Duchamp está dividido em seis capítulos: "Anarquismo, anartismo"; "A imagem líquida e os espelhos"; "O impossível"; "Hasard, Hagard"; "A condição acefálica: Duchamp e António Pedro"; e "Washington \& Bolívar: alegorias de gênero e origem". Capítulos que são atravessados pelo encontro amoroso de Marcel Duchamp com a escultora Maria Martins. É deste encontro amoroso que Antelo rearma o processo artístico do autor de Dados (1947), ao mesmo tempo em que reconstitui o percurso da arte latino-americana frente à vanguarda europeia. Nesse processo, em Maria com Marcel, o vazio, na forma de aborrecimento, relatado por Duchamp em suas correspondências durante a estada na capital portenha, é lido, por Raúl Antelo, pelo viés da erudição, aproximando arquivos e pessoas. É sempre pela erudição que Antelo expõe, esclarece, e, ao mesmo tempo, torna a passagem de Marcel 
Duchamp pela América Latina, ao invés de "aborrecida", excitante e reveladora. Dessa maneira, o autor traz para a discussão não somente o que já está consolidado pela crítica, mas especialmente o que foi esquecido, o lado periférico de todo o processo de Duchamp, o qual pode ser totalmente relacionado aos meses que passou em Buenos Aires. O leitor depara-se, também, com um palimpsesto composto por imagens e textos, por construções que mais que narrar, apresentam um procedimento ímpar de reler/ escovar a história a contrapelo, como lemos nas teses sobre a história de Walter Benjamin ${ }^{6}$.

$\mathrm{Na}$ edição brasileira, temos o privilégio de contar com algumas alterações e acréscimos que contribuem e completam a edição anterior. Por exemplo, no segundo capítulo "A imagem líquida e os espelhos", foi acrescentado o texto: "Mar, mãe, monumento". Neste texto, Antelo relaciona a figura do mar com referências da cultura de massa, por exemplo, a ampola de 50cc de ar de Paris (1919) ou a poesia de Charles Baudelaire: "o mar é teu espelho, tu contemplas tua alma / no desenrolar infinito de sua vaga / E o seu espírito não é um abismo menos amargo". O autor de Ausências (2009) lembra, também, que a nova "teorização da modernidade é objeto da poesia, mas, simultaneamente, também da psicanálise." Assim, com as imagens do mar na modernidade, Antelo mostra que, mais que uma teoria crítica, há em Duchamp "uma teoria do sujeito para além da biologia e, ao mesmo tempo, aquém da animalidade" (p. 82). Às imagens do mar são adicionadas a leitura de Sigmund Freud e Jacques Lacan, que nos levam a outras imagens e textos, onde lemos Man Ray com Cruz e Souza e Mário de Andrade. Antelo, por sua vez, não deixa passar em branco as experiências visuais do pintor Victor Meirelles:

Antes mesmo das especulações de Duchamp ou Man Ray, a respeito do mar,
o pintor Victor Meirelles realizou, com esse intuito, entre 1886 e 1888 , um
"Panorama circular da cidade do Rio de Janeiro", que seria exibido em 1899
na Exposição Universal de Paris, seguido, em 1894, de outro panorama,
"Entrada da Esquadra Legal". Um anúncio da época alardeava tratar-se de
"grande tela panorâmica de 115m de comprimento por 14 e meio de largura",
cujo efeito extraordinário "produz no espectador a mesma impressão de
realidade, como se o observador estivesse no lugar verdadeiro" (p. 87).

Para finalizar a discussão sobre o mar, Raúl Antelo traz à baila o erotismo e com ele o escritor Rubén Darío, finalizando com um poema de Haroldo de Campos "Thalassa, thalassa" que pode ser conferido na página 89 de Maria com Marcel.

Há, também, o acréscimo do texto "Xul e Maria", no quarto capítulo, "Hasard, Hagard", em que Antelo nos presenteia com a transcrição do texto "A cobra grande" de Xul Solar ${ }^{7}$, lembrando que o escritor argentino era "aplicado leitor da rapsódia de Mário de Andrade, [e por isso] não deve surpreender que Xul associe, em sua versão, a Cobra Grande à Via Láctea e, mais importante talvez do que isso, aos fins de nossa análise, o texto mostra o transformismo hermafrodita do animal totêmico, bem ao gosto de Maria Martins" (p. 175).

$\mathrm{Na}$ conclusão, também foram acrescentados outros fragmentos: "Imitação, sugestão, sensação"; "VERS. Rumo à história futura"; "Estereoscopia de Buenos

\footnotetext{
${ }^{6}$ BENJAMIN, Walter. "Sobre o conceito da história". In. Sérgio Paulo Rouanet. 7 ed. São Paulo: Brasiliense, 1994. . Magia e técnica, arte e política. Trad.

${ }^{7}$ Xul Solar, pintor e escritor modernista argentino, criou híbridas línguas poéticas, como o neocriollo e a panlíngua.
} 
Aires". E foi retirado, suprimido da edição brasileira, "Nudos", um glossário em que alguns termos "infraleve", "máquina celibatária o soltera", "ready-made", "retard", "regard" e "sociedad anônima" são esclarecidos, na forma de verbetes, como por exemplo:

Regard. Mirada. A partir de los artilugios ópticos surrealistas, la mirada opera según tres modos. Hay uma mirada ontogenética, que es la mirada del dios creador, en que el objeto emerge como producto de uma contemplación sin existencia previa, gracias a la cual los objetos adquieren materialidad fantasmática y antinaturalista. Hay además uma mirada catalogadora, em que el ojo, como demiurgo platônico, provoca alteraciones, especulaciones, simulacros. Pero hay em fin una mirada que recorta y aísla, en que el ojo se comporta como una máquina fotográfica. Este registro, que engloba a los anteriores, observa el mundo como un reservorio de posibilidades de tal modo que el unverso entero se transforma en un ready-made. En registro se consolida la aventura anti-ocularcéntrica.

Por isso é que se pode dizer que o livro, que tem como pano de fundo o romance entre Marcel e Maria, é apaixonante, sim, porque mais que narrar uma história de amor modelada em cera e desejo, Raúl Antelo nos apresenta e nos envolve em uma leitura em que a arte do século XX brota, explode como em uma primavera que por si só expõe os contatos, o que acaba colocando o romance dos protagonistas em segundo plano. Por isso, mais que apresentar uma leitura singular da modernidade via América Latina, Maria com Marcel demonstra como é possível colocar em movimento arquivos, histórias, dados e procedimentos. Além do mais, para finalizar, pode-se afirmar que Maria com Marcel é um livro denso. E, além disso, reivindica mais que leitores disciplinados: requer leitores que se deixem envolver, que se permitam compartilhar, tanto a tragédia quanto as bodas, tanto o desejo quanto a espera. 